\title{
Interculturalidade, interepistemicidade e decolonialidade: a pesquisa de co-labor
}

\author{
Cross-cultural, inter-epistemic, and decolonialization issues in \\ coworking research
}

Interculturalidad, interepistemicidad y decolonalidad:

la investigación co-laboral

SALAZAR JG, WALSH C. PENSAR SEMBRANDO/SEMBRAR PENSANDO CON EL ABUELO ZENÓN. QUITO: UNIVERSIDAD ANDINA SIMÓN BOLÍVAR/EDICIONES ABYA-YALA; 2017. 264 P. ISBN 978-9978-19-786-8.

doi: 10.1590/0102-311X00145519

O que é conhecimento? Como, quem e onde se produz conhecimento? Juan Garcia Salazar e Catherine Walsh, no livro Pensar Sembrando/ Sembrar Pensando con el Abuelo Zenón 1, refletem sobre a importância de resgatar e valorizar a transmissão oral das histórias e do conhecimento ancestral, como uma potente prática de resistência contra a colonização de territórios e saberes. Organizado em cinco capítulos, o livro traz 29 textos e 17 imagens que registram a memória dos povos afro-equatorianos, e provocam uma reflexão sobre as práticas hegemônicas e de poder (re)produzidas pelas estruturas do "esquema acadêmico e a lógica ocidental de produção de conhecimento" 1 (p. 11), que tendem a desvalorizar tudo aquilo que não é legitimado como científico.

Nessa coprodução, Salazar \& Walsh investem na metodologia-pedagogia de co-labor, que privilegia a pluralidade de experiências e saberes compartilhados, por meio de reflexões dialógicas com homens e mulheres que vivenciam suas práticas e fazeres cotidianos fora dos espaços da academia. Argumentam que "o conhecimento não se produz sozinho na academia, mas também na prática social, política e cultural; nos espaços não só individuais, mas também comunitários, coletivos e até intergeracionais, e para fins que nem sempre apontam para "a ciência", mas para "as ciências" através da existência e da vida" 1 (p. 9).

O principal interlocutor dos autores é o "avô Zenón”, guardião da palavra e semeador dos mandatos culturais do seu povo, que foi criado por Salazar como mensageiro e representante de "todos e todas de origem africana, nascidos na região do Pacífico" 1 (p. 22). Longe de ser uma figura fantasiosa ou caricata, "avô Zenón” é um personagem que verbaliza sobre "o que se guarda na memória coletiva dos povos e nações que tiveram $o$ direito à escrita negado" 1 (p. 24). Ele traz a força vital para os enfrentamentos contra as ameaças que colocam em risco territórios e direitos ancestrais, arquitetadas, principalmente, pelo Estado e pelas indústrias extrativistas.

O capítulo um, Sobre Siembras en y Desde los Territorios Ancestrales, discorre acerca da importância do cultivo das "sementes culturais" para a (re)construção identitária do povo afro-equatoriano e a relação com o direito aos territórios ancestrais, que são um "espaço [político, coletivo e compartilhado] de vital importância para garantir a reprodução étnica, social e cultural” 1 (p. 53). A semeadura cultural é um ato de luta e resistência contra os processos de aculturação, desumanização e expropriação impostos aos povos de origem africana desde os tempos da escravidão. Também, é uma prática de autoafirmação e autorreparação coletiva que resgata e reinventa 
saberes e práticas culturais, "recriando suas próprias formas de vida" 1 (p. 46). A favor da representatividade e da inclusão das diferenças, esse exercício desafia a política de produção de conhecimento dominante, que projeta leituras distorcidas sobre racionalidades e existências subjugadas como inferiores, diferentes, estranhas e atrasadas.

O capítulo dois, Identidad, Saber y Hacer Cultu$\mathrm{ral}$, discorre sobre os frutos das lutas de emancipação e de resistência étnica, coletiva, existencial e cultural conquistadas pelos herdeiros e herdeiras da diáspora africana, e trata sobre a finalidade dos mandatos ancestrais. Destaca-se o mandato "casa adentro e casa afuera", que por centenas de anos tem orientado os povos afro-equatorianos a cultivarem suas raízes culturais, enfatizando a importância de se fortalecerem contra as várias formas de opressão e violência que os forçam a deixar de ser quem verdadeiramente são (p. 95 e 98). Salazar \& Walsh alertam sobre os perigos da historiografia oficial e refletem sobre os limites de se pensar a identidade apenas sob o viés conceitual, já que sua definição não compreende, genuinamente, a identidade como um constructo que envolve "propostas sociais, econômicas e politicas que vem dos coletivos" 1 (p. 99), além dos já conhecidos aspectos étnicos e culturais.

As representações que enquadram a cultura afro-equatoriana como mero folclore exprimem sentidos pejorativos que invisibilizam e anulam os significados que sustentam as práticas culturais ancestrais. $\mathrm{O}$ avô Zenón frisa que, para combater os processos de dominação e discriminação impostos pelo Estado, uma das estratégias é construir diálogos interculturais nos espaços "casa afuera" para aprender a conviver e respeitar as diferenças, questionando, por exemplo, o apagamento da cultura afro-esmeraldina nos conteúdos oficiais do sistema educacional equatoriano. Mais do que simplesmente reconhecer a diversidade, a interculturalidade é uma prática orientada para a transformação das inequidades e das desigualdades sofridas por grupos e povos excluídos pelas estruturas de poder.

Os textos do capítulo três, El Caminar y Andar de la Tradición Oral, refletem sobre as estratégias pedagógicas da tradição oral, que são vitais para o ensino e o aprendizado dos mandatos ancestrais. Fundamentalmente, Salazar, Zenón e Walsh problematizam como a modernidade está enfraquecendo a manutenção dos saberes locais, prejudicando as relações intergeracionais nas comunidades quilombolas e, consequentemente, a transmissão e a busca pelo conhecimento. Diferentemente da estrutura científico-acadêmica hegemônica, o mandato "caminar e andar, andar e caminar" vai além do seu sentido literário e faz um convite ao diálogo, à troca e à interação entre diferentes gerações para o processo ensino/aprendizagem das palavras ancestrais, que, através, por exemplo, de lendas, cânticos, saberes curativos, adivinhações e trava-línguas, falam sobre a cosmovisão, valores e práticas culturais que organizam a vida dos povos e comunidades tradicionais.

No capítulo Resistencia, Historia, Memoria, é apresentado um protesto contra a participação marginalizada dos negros na história de formação do Equador como nação. Trata-se de um manifesto que, ao passo que reivindica o reconhecimento do protagonismo de atores e sujeitos coletivos, ilumina narrativas negligenciadas pelos marcos legais dominantes e ressignifica os estereótipos e os estigmas lançados pela historiografia oficial. Para "reordenar a história em uma chave diferente" 1 (p. 168), os autores afirmam a importância da pedagogia cimarrona para projetar uma nova leitura sobre os atos de subversão, insurgência e resistência dos povos quilombolas ao poder colonial, recompondo, assim, os caminhos e os processos das lutas pela afirmação identitária dos povos de origem africana.

Finalmente, em Desterritorialización, os autores denunciam o andamento de uma nova diáspora, tramada por arranjos geopolíticos modernos e projetos extrativistas. Aprovado pelo Estado, esse processo se impõe aos territórios ancestrais e coloca em risco a existência das comunidades afro-equatorianas e suas raízes culturais, que outrora foram semeadas pelos antepassados que formaram os primeiros quilombos do norte de Esmeraldas. Frente às falsas promessas de desenvolvimento, crescimento e inclusão anunciadas pela lógica moderna de colonização, os autores refletem sobre a importância dos princípios do estar bien colectivo, um ensinamento ancestral que trata sobre territorialização, pertencimento e o compromisso de cuidar da mãe natureza e dos seres que nela habitam, sempre de forma sagrada, harmônica, consciente e respeitosa.

Ainda que os saberes ancestrais apresentados no livro habitem o norte de Esmeraldas, no 
Equador, esses ensinamentos não se limitam à cultura local. Sem dúvidas, Salazar, Walsh e Zenón nos convidam a "um outro pensar e semear" 1 (p. 134) para aprendermos a desaprender práticas científicas colonizadoras que reforçam assimetrias na produção de conhecimento 1,2. Para tanto, é indispensável que pesquisadoras e pesquisadores invistam em projetos que desafiem as estruturas da geopolítica epistêmica dominante, e, tal qual a proposta da metodologia de co-labor, rompam com práticas intelectuais que excluem linguagens e formas distintas de pensar, conhecer, classificar, subalternizar e marginalizar sujeitos, experiências e fazeres. Essas reflexões alertam para o compromisso político do/a pesquisador/a com a justiça social, com a interculturalização da palavra e a descolonização do conhecimento na pesquisa científica 1,3,4.

Janaina Alves da Silveira Hallais 1

Nelson Filice de Barros 1

1 Universidade Estadual de Campinas, Campinas, Brasil. jhallais@gmail.com

\section{Colaboradores}

J. A. S. Hallais e N. F. Barros contribuíram na leitura do livro, discussão e redação da resenha.

\section{Informações adicionais}

ORCID: Janaína Alves da Silveira Hallais (00000001-6416-9559); Nelson Filice de Barros (00000002-5404-1516).

1. Salazar JG, Walsh C. Pensar sembrando/sembrar pensando con el Abuelo Zenón. Quito: Universidad Andina Simón Bolívar/Ediciones Abya-Yala; 2017.

2. Walsh C. Respuestas a un cuestionario: posiciones y situaciones. In: Richard N, editor. En torno a los estudios culturales. Localidades, trayectorias, trayectorias y disputas. Buenos Aires: Consejo Latinoamericano de Ciencias Sociales; 2010. p. 93-106.

3. Levya X, Speed S. Hacia la investigación descolonizada: nuestra experiencia de co-labor. In: Levya X, Burguete A, Speed S, editores. Gobernar (en) la diversidad: experiencias indígenas desde América Latina. Hacia la investigación de co-labor. Mexico DF: Centro de Investigaciones y Estudios Superiores en Antropologia Social, Facultad Lationamericana de Ciencias Sociales; 2008. p. 65-107.

4. Muniz MLC. A busca pela palavra roubada: estratégias de comunicação e articulação de povos e nacionalidades indígenas na Amazônia equatoriana [Tese de Doutorado]. Brasília: Universidade de Brasília; 2016. 